\title{
A treatment paradigm for high-grade brain arteriovenous malformations: volume-staged radiosurgical downgrading followed by microsurgical resection
}

\author{
Adib A. Abla, MD, ${ }^{1}$ William Caleb Rutledge, MD, ${ }^{1}$ Zachary A. Seymour, MD, ${ }^{2}$ Diana Guo, BA, ${ }^{3}$ \\ Helen Kim, PhD, ${ }^{3}$ Nalin Gupta, MD, PhD, ${ }^{1}$ Penny K. Sneed, MD, ${ }^{2}$ Igor J. Barani, MD, ${ }^{2}$ \\ David Larson, PhD, MD, ${ }^{2}$ Michael W. McDermott, MD, ${ }^{1}$ and Michael T. Lawton, MD ${ }^{1,3}$ \\ Departments of ${ }^{1}$ Neurological Surgery and ${ }^{2}$ Radiation Oncology, and ${ }^{3}$ Center for Cerebrovascular Research, University of \\ California, San Francisco, California
}

OBJECT The surgical treatment of many large arteriovenous malformations (AVMs) is associated with substantial risks, and many are considered inoperable. Furthermore, AVMs larger than $3 \mathrm{~cm}$ in diameter are not usually treated with conventional single-session radiosurgery encompassing the entire AVM volume. Volume-staged stereotactic radiosurgery (VS-SRS) is an option for large AVMs, but it has mixed results. The authors report on a series of patients with highgrade AVMs who underwent multiple VS-SRS sessions with resultant downgrading of the AVMs, followed by resection.

METHODS. A cohort of patients was retrieved from a single-institution AVM patient registry consisting of prospectively collected data. VS-SRS was performed as a planned intentional treatment. Surgery was considered as salvage therapy in select patients.

RESULTS Sixteen AVMs underwent VS-SRS followed by surgery. Four AVMs presented with rupture. The mean patient age was 25.3 years (range 13-54 years). The average initial Spetzler-Martin grade before any treatment was 4 , while the average supplemented Spetzler-Martin grade (Spetzler-Martin plus Lawton-Young) was 7.1. The average AVM size in maximum dimension was $5.9 \mathrm{~cm}$ (range 3.3-10 cm). All AVMs were supratentorial in location and all except one were in eloquent areas of the brain, with 7 involving primary motor cortex. The mean number of VS-SRS sessions was 2.7 (range 2-5 sessions). The mean interval between first VS-SRS session and resection was 5.7 years. There were 4 hemorrhages that occurred after VS-SRS. The average Spetzler-Martin grade was reduced to 2.5 (downgrade, -1.5 ) and the average supplemented Spetzler-Martin grade was reduced to 5.6 (downgrade, -1.5). The maximum AVM size was reduced to an average of $3.0 \mathrm{~cm}$ (downsize $=-2.9 \mathrm{~cm}$ ). The mean modified Rankin Scale $(\mathrm{mRS})$ scores were 1.2, 2.3, and 2.2 before VS-SRS, before surgery, and at last follow-up, respectively (mean follow-up, 6.9 years). Fifteen AVMs were cured after surgery. Ten patients had good outcomes at last follow-up ( 7 with mRS Score 0 or 1 , and 3 with mRS Score 2). There were 2 deaths (both mRS Score 1 before treatment) and 4 patients with mRS Score 3 outcome (from mRS Scores 0,1 , and 2 [ $n=2]$ ).

CONCLUSIONS Volume-staged SRS can downgrade AVMs, transforming high-grade AVMs (initially considered inoperable) into operable AVMs with acceptable surgical risks. This treatment paradigm offers an alternative to conservative observation for young patients with unruptured AVMs and long life expectancy, where the risk of hemorrhage is substantial. Difficult AVMs were cured in 15 patients. Surgical morbidity associated with downgraded AVMs is reduced to that of postradiosurgical/preoperative supplemented Spetzler-Martin grades, not their initial AVM grades.

http://thejns.org/doi/abs/10.3171/2014.10.JNS1424

KEY WORDS arteriovenous malformation; supplementary grade; Spetzler-Martin grade; stereotactic radiosurgery; Gamma Knife; microsurgical resection; vascular disorders

ABBREVIATIONS AVM = arteriovenous malformation; $\mathrm{mRS}$ = modified Rankin Scale; SRS = stereotactic radiosurgery; $\mathrm{SS}$ = single-session; VS = volume-staged . SUBMITTED January 5, 2014. ACCEPTED October 14, 2014.

INCLUDE WHEN CITING Published online November 28, 2014; DOI: 10.3171/2014.10.JNS1424.

DISCLOSURE The authors report no conflict of interest concerning the materials or methods used in this study or the findings specified in this paper. 


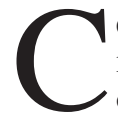
ONTEMPORARY management of brain arteriovenous malformations (AVMs) requires the coordination of several treatment modalities including endovascular embolization, microsurgical resection, stereotactic radiosurgery (SRS), and observation. The Spetzler-Martin grading system helps individualize management by separating patients into 2 distinct groups: low-grade (Grades I, II, and most III) and high-grade AVMs (some Grade III, and Grades IV and V). Low-grade AVMs are generally small, superficial, and/or noneloquent with low morbidity rates associated with resection and high obliteration rates associated with SRS, making both modalities acceptable. In contrast, high-grade AVMs are large, deep, and usually involve eloquent brain areas. Not surprisingly, resection is associated with substantial morbidity, ${ }^{18,26}$ while SRS is associated with low obliteration rates. Therefore, high-grade AVMs are some of the most challenging lesions because they require an understanding of when to simply observe, which runs against our clinical instinct to intervene to protect the patient from hemorrhage. The surgical indications for patients with high-grade AVMs include previous hemorrhage, an existing significant permanent deficit, progressive neurological deficit related to vascular steal, or an associated arterial or intranidal aneurysm. ${ }^{9}$ In young patients who do not have any of these features, observation is usually recommended, but this option is based on a lack of acceptable alternatives. A treatment paradigm is needed for these patients with substantial lifetime hemorrhage risks.

Single-session SRS (SS-SRS) is not effective for highgrade AVMs because nidal volumes greater than 14 or 15 $\mathrm{cm}^{3}$ (approximately $3 \mathrm{~cm}$ in diameter) require reductions in the marginal dose below 16 Gy to avoid adverse radiation complications, ${ }^{19}$ while $16-$, 18-, and $20-$ Gy marginal doses are associated with $70 \%, 80 \%$, and $90 \%$ obliteration rates for AVMs overall. ${ }^{22}$ Volume-staged SRS (VS-SRS) is a newer strategy that divides a large AVM into 2 or 3 smaller portions that are treated at separate stages enabling each portion to receive a higher dose. ${ }^{12,22}$ The higher dose may be associated with a greater likelihood of response, while the separation of stages by months and proper alignment of staged volumes may reduce complications.

Volume-staged SRS has improved rates of AVM obliteration compared with SS-SRS, but as a sole form of therapy, cure rates are low. 3,11,12,22,25,31 VS-SRS of high-grade AVMs often results in a partial response, which may transform inoperable AVMs into low-grade lesions with a more acceptable surgical risk profile. Microsurgery has been used effectively and with reduced morbidity as a salvage technique after SS-SRS. ${ }^{24,29}$ Included in these reports are patients treated with additional sessions of SRS to residual $\mathrm{AVM}$ at the end of the latency period, which differs from upfront volume-staged therapy. However, the planned combination of VS-SRS plus microsurgery has not been evaluated as part of a treatment paradigm for inoperable high-grade AVMs. Although it may have been conceived as early as 1998 by the Pittsburgh group, ${ }^{4}$ publications are limited to a single case report. Therefore, we reviewed our experience with microsurgical AVM resection after VSSRS to advance the concept of downgrading inoperable AVMs and facilitating curative resection with radiosur- gery. This multimodality approach differs from salvage surgery after SS-SRS and from VS-SRS as a stand-alone approach. Although we and others have published case series on both VS-SRS alone and SS-SRS plus surgery, there are no case series published on VS-SRS plus surgery. Our experience with VS-SRS plus surgery described in this report establishes its effectiveness in select patients with AVMs that initially were overwhelming.

\section{Methods \\ Study Design}

This study was approved by the institutional review board and was performed in compliance with Health Insurance Portability and Accountability Act regulations. Patients with AVMs undergoing both VS-SRS and microsurgery and were identified from 2 prospectively maintained databases, one from the University of California, San Francisco Brain Arteriovenous Malformation Study Project and the other from the Gamma Knife stereotactic radiosurgery service. Data, including components of the Spetzler-Martin ${ }^{26}$ and supplemented Spetzler-Martin ${ }^{18}$ grading systems and modified Rankin Scale (mRS) outcomes, were collected from the prospective databases and additional data were gathered retrospectively.

\section{Patients}

Volume-staged SRS was initiated at our institution in 1992 and patients included in this study were treated during a 20-year period (from 1992 to 2012). All VS-SRS was performed or supervised by senior faculty (M.W.McD., 1992-2012) and AVM resections were performed by the senior author (M.T.L.) over a 16-year period from 1997 to 2013 .

\section{Treatment Strategy}

Patients with AVM were reviewed at weekly multidisciplinary conferences attended by neurosurgeons, neurologists, neuroradiologists, interventional neuroradiologists, radiation oncologists, and Gamma Knife coordinators. Patients with high-grade AVMs deemed unfavorable for open microsurgery were initially treated with VS-SRS. AVM response to VS-SRS was evaluated at the end of an approximately 3-year latency period, and AVMs with a decreased Spetzler-Martin grade or significant radiation response were reconsidered for microsurgical resection. Postradiosurgical AVMs deemed more favorable for open microsurgery were offered this additional treatment, with or without preoperative embolization.

\section{Volume-Staged Radiosurgical Technique}

Our technique for VS-SRS for large AVMs was tabulated in 69 patients in a separate report (unpublished data, Seymour et al., International SRS Congress, June 19, 2013). Patients underwent stereotactic MRI, MR angiography, and cerebral angiography prior to the first VS-SRS session. During the first session the entire AVM volume was planned and then the portion of the AVM closest to the primary arterial input was targeted first. In subsequent sessions repeat MRI/MR angiography was performed, 
and the treatment plan from the first session was coregistered to the new imaging data set to avoid overlap of dose in brain adjacent to the AVM. ${ }^{6}$ In general, these patients had AVMs larger than $10 \mathrm{~cm}^{3}$ in volume in eloquent and/ or deep locations with minimal or no neurological deficits, or the patients had refused surgery. Individual radiosurgical sessions were separated by an interval of 3-6 months. In those patients treated in the second half of the experience (after 2005, considered Era 2) the volume per stage was decreased to less than $8-10 \mathrm{~cm}^{3}$ and the dose per stage increased to $\geq 17 \mathrm{~Gy}$. MRI was performed at 12-month intervals following completion of VS-SRS, and angiography was performed at 36 months. AVMs that were downgraded or favorably changed by VS-SRS after 3 years were then treated by open microsurgery. Some AVMs that were not downgraded or were favorably changed by VS-SRS after 3 years were considered for salvage radiosurgery. Patients with AVMs that were not downgraded or favorably changed by VS-SRS, and were still deemed unfavorable for open microsurgery, were not selected for microsurgery.

\section{Outcomes}

Patient outcomes were assessed using the mRS during posttreatment clinic visits, subsequent hospital admissions, or telephone interviews by research personnel not involved in the patients' care. A good outcome was defined as a final mRS score of $0-2$, while a poor outcome was defined as mRS score greater than 2. Functional improvement was defined as a decrease in mRS score from the initial examination at presentation to the final followup examination. Angiography demonstrating complete AVM resection and no residual arteriovenous shunt was required for AVM obliteration.

\section{Statistical Analysis}

Comparisons between groups were made using the Fisher exact test for categorical variables, using the chisquare test for categorical variables with more than 2 categories, and with the Wilcoxon-Mann-Whitney test for comparison of continuous variables; $p$ values $<0.05$ were considered statistically significant.

\section{Results \\ Overall Treatment Results}

The treatment paradigm for AVMs with Spetzler-Martin Grades III, IV, or V is shown in Fig. 1 . Of 402 patients with high-grade AVMs managed since 2000, 54 were selected for observation alone, 199 underwent embolization and resection, 37 underwent embolization alone, and 112 underwent some form of SRS (either SS-SRS or VS-SRS). In the period between 1992 and 2012, 74 patients were treated with VS-SRS. Eight AVMs (10.8\%) were cured, $50(67.6 \%)$ were unchanged or remained unfavorable for microsurgery, and $16(21.6 \%)$ were selected for microsurgery. Microsurgical treatments were performed during the years 2000 to 2012 in all patients except one (1998).

The group of 16 patients with radio-responsive but persistent AVMs had a mean age of 25 years (range 13-54 years) and included 10 women and 6 men (Table 1). Comparison of patients treated with VS-SRS plus surgery and
VS-SRS alone is shown in Table 1. Only 4 patients (25\%) presented with hemorrhage while the remaining patients presented with seizures or other symptoms (Table 2). At presentation, 4 patients had Spetzler-Martin Grade III AVMs (25\%), 8 had Grade IV AVMs (50\%), and 4 had Grade V AVMs (25\%) (Tables 2 and 3). Overall, 15 AVMs $(93.8 \%)$ were located in eloquent brain regions, $10(62.5 \%)$ had deep drainage, and 7 (43.8\%) had a maximum diameter greater than $6 \mathrm{~cm}$. All were located in the supratentorial compartment and $7(43.8 \%)$ involved the primary motor cortex. Ten AVMs (62.5\%) had a diffuse nidus demonstrated by angiography, and 12 (75\%) were unruptured, raising the supplemented Spetzler-Martin grades to greater than 6 in 9 patients $(56.2 \%)$ (Table 3$)$.

\section{VS-SRS Treatment}

The mean number of VS-SRS sessions was 2.7 (range 2-5 sessions) (Table 1). Before VS-SRS, the average Spetzler-Martin grade was 4.0 and the average supplemented Spetzler-Martin grade was 7.1, with an average AVM diameter of $5.9 \mathrm{~cm}$. After VS-SRS, the average SpetzlerMartin grade decreased to 2.5, a downgrade of 1.5 points. Similarly, the average supplemented Spetzler-Martin grade decreased to 5.6, a downgrade of 1.5 points. The average AVM diameter decreased to $3.0 \mathrm{~cm}$, with a mean reduction in nidus size of $2.9 \mathrm{~cm}$. After VS-SRS, 14 of 16 AVMs had Spetzler-Martin grades less than or equal to Grade III, and 13 of 16 AVMs had supplemented SpetzlerMartin grades less than or equal to Grade 6, the usual cutoffs for surgical intervention.

\section{Microsurgical Treatment}

The mean interval between the initiation of VS-SRS and microsurgical resection was 5.7 years (range 0.5-18.7 years) (Tables 1 and 2). Four patients experienced a hemorrhage during the latency period, prompting surgery before the usual 3-year reevaluation. Six patients underwent preoperative embolization after VS-SRS (Table 2).

Of the 16 patients undergoing surgery, 1 had a residual AVM after all treatment. One patient with a 5-cm-diameter AVM located in Wernicke's area in the dominant hemisphere underwent an awake craniotomy with speech mapping. The AVM was not completely resected to preserve the language cortex. Postoperative angiography confirmed curative AVM resection in 15 patients (93.8\%). A summary of angiographic images, initially, before surgery, and following surgery is shown in Fig. 2. The location of the AVMs treated in this series is graphically depicted in Fig. 3.

\section{Patient Outcomes}

The mean mRS scores at presentation, before surgery, and at last evaluation were $1.2,2.3$, and 2.2 , respectively (Table 1). The mean duration of follow-up was 6.9 years (range $0.5-19.5$ years). Ten patients (62.5\%) had good outcomes at last follow-up: mRS Scores 0-1, 7 patients; and mRS Score 2, 3 patients (Table 2).

Four patients had poor outcomes (mRS Score 3, all experienced deterioration after treatment). One patient's condition deteriorated after VS-SRS (mRS Score 2 to 3, Case 


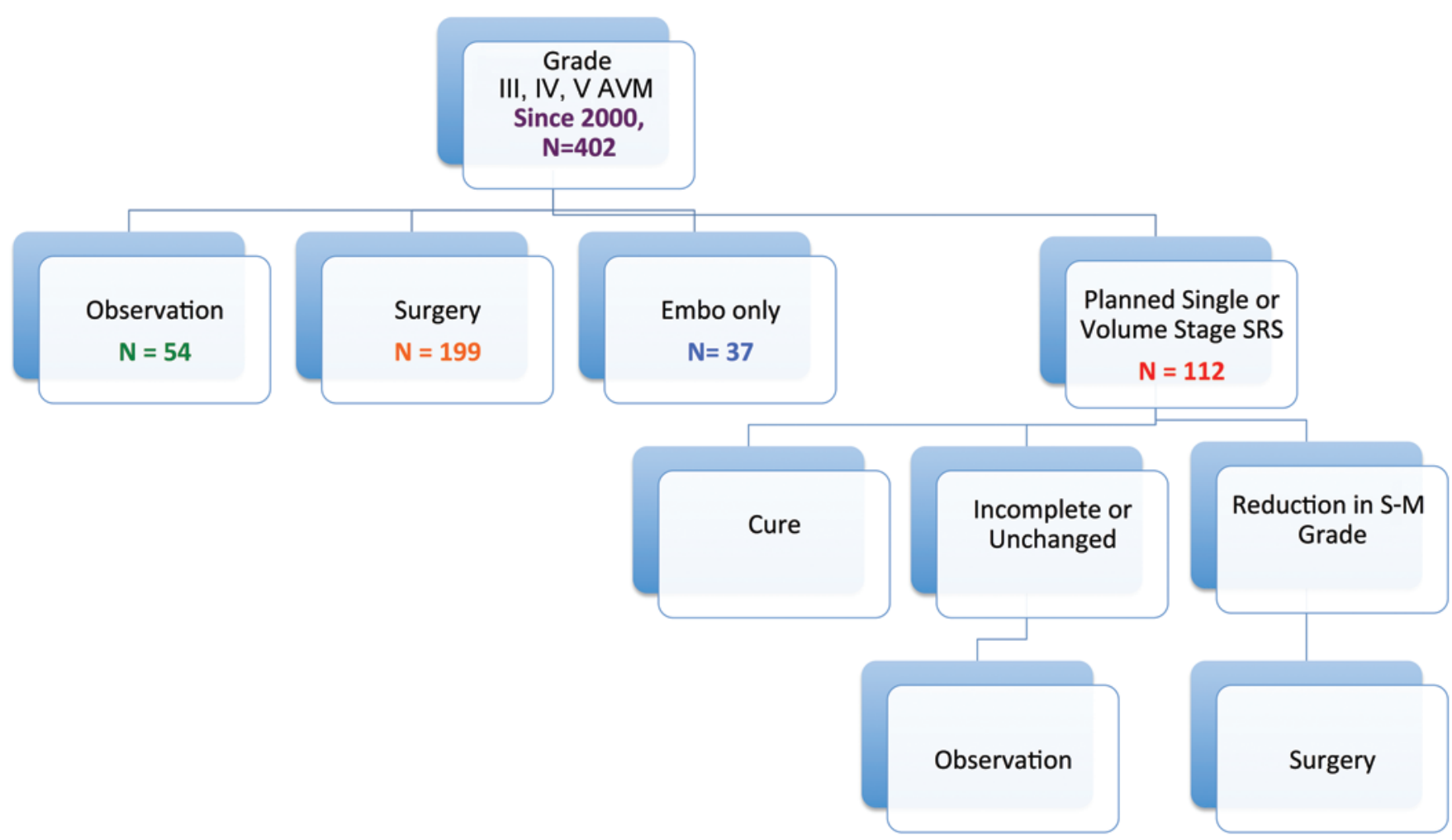

FIG. 1. Flow diagram illustrating the overall management of high-grade AVMs. Embo = embolization; S-M = Spetzler-Martin. Figure is available in color online only.

2); one patient's condition deteriorated after a hemorrhage during the latency period following VS-SRS (mRS Score 1 to 5, Case 7); and one patient's condition deteriorated after resection of an AVM in the motor cortex (mRS Score 2 to 3, Case 1). An additional patient with an insular/basal ganglia AVM underwent uncomplicated AVM resection without neurological sequela, but worsened 2 days after surgery because of a delayed venous infarction (mRS Score 0 to 3 , Case 13).

Two patients died (treatment mortality, 12.5\%). One patient with a paramedian frontal AVM involving the motor cortex presented with a hemorrhage and minor neurological deficits but then experienced rehemorrhage 6 months after completing VS-SRS. Although she was aggressively treated with hemicraniectomy at an outside hospital, and AVM resection after transfer to our institution, she did not emerge from coma and died. The second patient had a similar but much larger AVM that presented after VSSRS with steno-occlusive changes in parasagittal veins and marked hemispheric edema. Resection was complicated by her limited venous drainage, intraoperative AVM rupture, and postoperative intracranial hypertension.

\section{AVM Grading and Risk Prediction With VS-SRS Plus Surgery}

In this series, VS-SRS downgrading plus microsurgery was an effective combination in the treatment of high-grade AVMs, with cure observed in 15 of 16 patients (93.8\%). This cure rate was significantly higher than VS-SRS alone (8 of 58 patients, $13.8 \%$; $\mathrm{p}<0.001$, Fisher exact test [Table
4]). Rates of mortality and latency hemorrhage were considerable for VS-SRS plus surgery $(12.5 \%$ and $25 \%$, respectively; Table 4) but not significantly different from the rates of mortality and hemorrhage associated with VS-SRS alone (19\% and 29.3\%, respectively; Table 4).

Based on our patients' initial Spetzler-Martin grade and data from the original publication of the SpetzlerMartin grading system, neurological morbidity or mortality would be expected in 4.0 patients (Table 5). However, after VS-SRS downgrading and using the same SpetzlerMartin data, neurological morbidity/mortality would be expected in 1.7 patients. Actual surgical neurological morbidity/mortality was observed in 3 patients, thus between these expected values, indicating that VS-SRS lowered the risk associated with AVM resection compared with AVM resection alone. Conversely, these morbidity and mortality figures indicate that the conventional risks predicted by the Spetzler-Martin grading system may be inaccurate with downgraded AVMs and may underestimate surgical risks. Total morbidity/mortality (6 patients) exceeded the highest expectations predicted by Spetzler-Martin grade when radiosurgical morbidity/mortality was included, due to radiation injury and latency hemorrhages (Total morbidity and mortality, Table 5).

Supplemented Spetzler-Martin grades at presentation accurately predicted total morbidity/mortality (expected, 6.2 versus actual, 6; Table 6), and supplemented grades of downgraded AVMs before surgery slightly overestimated the surgical morbidity/mortality (expected, 4.1 vs actual, 3), indicating that supplemented Spetzler-Martin scores 
TABLE 1. Characteristics in patients with Grade 3, 4, and 5 AVMs*

\begin{tabular}{|c|c|c|c|}
\hline Variable & VS-SRS + Surgery & VS-SRS Alone & $p$ Value \\
\hline \multicolumn{4}{|l|}{ Presentation } \\
\hline No. of patients & 16 & 58 & \\
\hline mRS score before GKRS & & & 0.628 \\
\hline Mean & 1.2 & 1.2 & \\
\hline Range & $0-5$ & $0-3$ & \\
\hline Prior hemorrhage & $4(25)$ & $23(39.7)$ & 0.383 \\
\hline Patient age at GKRS in yrs & & & 0.0132 \\
\hline Mean & 25.3 & 36.6 & \\
\hline Range & $13-54$ & $9-68$ & \\
\hline Age in yrs & & & 0.0714 \\
\hline$<20$ & $7(43.7)$ & $13(22.4)$ & \\
\hline $20-40$ & $7(43.7)$ & $21(36.2)$ & \\
\hline$>40$ & $2(12.5)$ & $24(41.4)$ & \\
\hline Diffuse & $10(62.5)$ & $31(53.4)$ & 0.580 \\
\hline Eloquence & $15(93.8)$ & $55(93.1)$ & 1.0 \\
\hline Deep venous drainage & $10(62.5)$ & $47(81.0)$ & 0.177 \\
\hline Maximum diameter in $\mathrm{cm}$ & & & 1.0 \\
\hline$<3$ & 0 & 0 & \\
\hline $3-6$ & $9(56.3)$ & $33(55.9)$ & \\
\hline$>6$ & $7(43.7)$ & $25(44.1)$ & \\
\hline S-M grade & & & 0.396 \\
\hline Mean & 4 & 4.17 & \\
\hline Range & III-V & III-V & \\
\hline \multicolumn{4}{|l|}{ GKRS result } \\
\hline \multicolumn{4}{|l|}{ GKRS treatments } \\
\hline Initial planned stages & & & 0.118 \\
\hline Mean & 2.31 & 2.14 & \\
\hline Range & $2-3$ & $2-4$ & \\
\hline Initial delivered stages & & & 0.0612 \\
\hline Mean & 2.25 & 2 & \\
\hline Range & $1-3$ & $1-3$ & \\
\hline \multicolumn{4}{|c|}{ Interval btwn 1st GKRS \& op in yrs } \\
\hline Mean & 5.7 & - & - \\
\hline Range & $0.5-18.7$ & & \\
\hline \multicolumn{4}{|l|}{ Preop mRS score } \\
\hline Mean & 2.3 & - & - \\
\hline Range & $0-5$ & & \\
\hline \multicolumn{4}{|l|}{ Preop S-M grade } \\
\hline Mean & 2.5 & - & - \\
\hline Range & I-IV & & \\
\hline \multicolumn{4}{|l|}{ Outcome } \\
\hline Total follow-up in yrs & & & 0.011 \\
\hline Mean & 6.9 & 4.12 & \\
\hline Range & $0.5-19.5$ & $0-17.6$ & \\
\hline Cure & $15(93.8)$ & $8(13.6)$ & $<0.0001$ \\
\hline Final mRS score & & & 0.979 \\
\hline Mean & 2.2 & 2.35 & \\
\hline Range & $0-6$ & $0-6$ & \\
\hline
\end{tabular}

GKRS = Gamma Knife radiosurgery; S-M = Spetzler-Martin; - = not applicable.

* Values are number of patients (\%) unless noted otherwise. Values in boldface are statistically significant. 


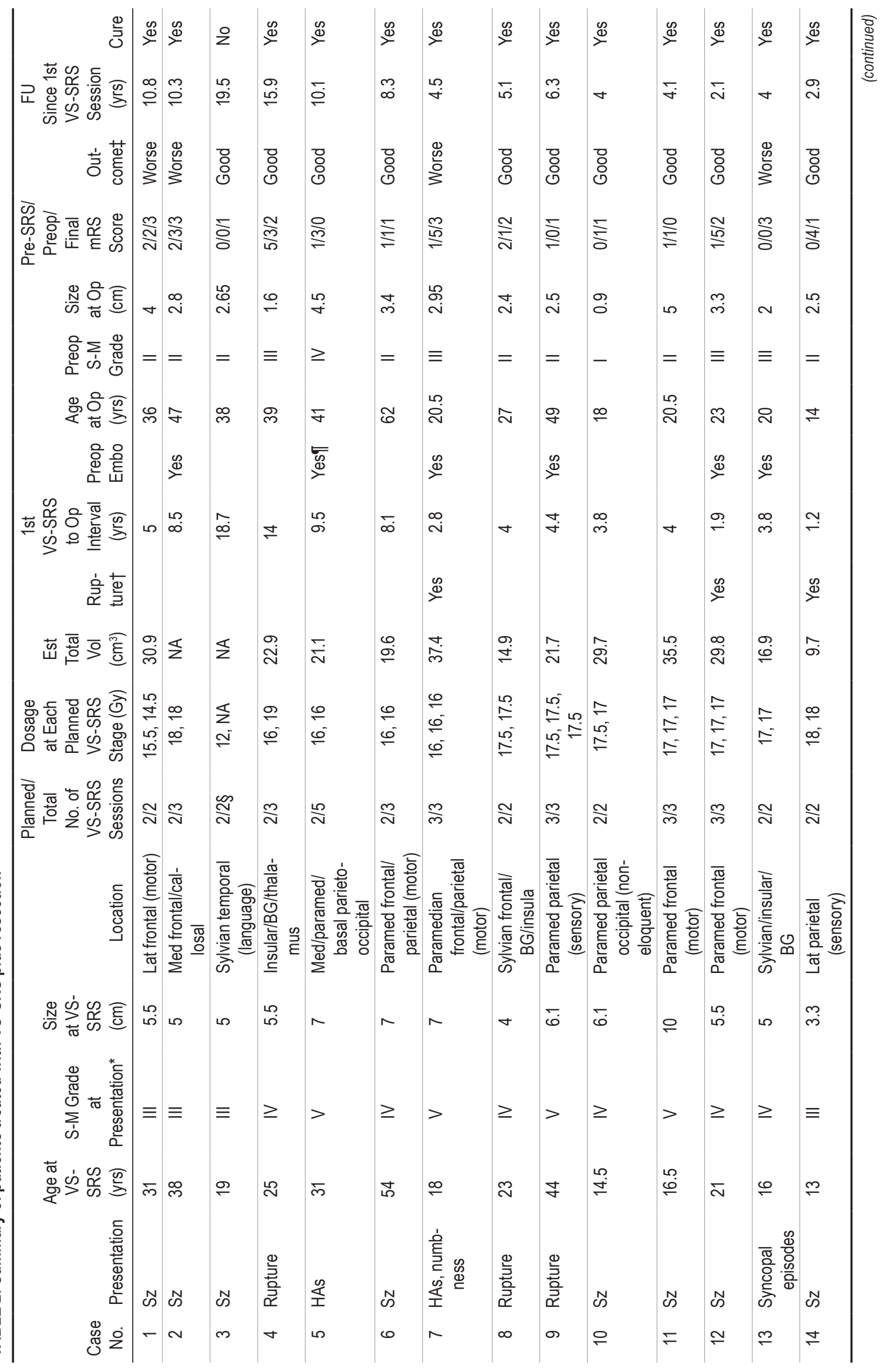


might provide more accurate risk prediction than nonsupplemented scores.

Cure rates with VS-SRS alone and with VS-SRS plus surgery at our institution are compared with SRS results in the literature, as are hemorrhage rates after SRS for those with high-grade or eloquent lesions or those undergoing multiple SRS treatments (Table 7). ${ }^{1-3,8,10-15,17,21,22,24,25,29-32}$

\section{Discussion}

\section{A New Treatment Paradigm for High-Grade AVMs?}

Patients with high-grade AVMs usually have 3 management options: 1) observation, 2) staged embolization plus microsurgical resection, and 3) VS-SRS. Staged embolization of large AVMs with high blood flow and cerebral steal occludes large feeding arteries in different vascular territories and redirects blood flow to dysautoregulated arteries in adjacent brain in a stepwise manner, rather than all at once during surgery. ${ }^{27}$ Although Spetzler and colleagues championed this strategy and reported an experience with 20 patients with morbidity and cure rates of $15 \%$ and $90 \%,{ }^{27}$ respectively, they now favor observation. ${ }^{9}$ In their consecutive series of 73 patients with Grade IV and V AVMs, only 4 patients (5\%) underwent complete surgical removal and 55 patients (75\%) were observed with an overall hemorrhage rate of $1.5 \%$ per year, which is less than that reported for low-grade AVMs. ${ }^{9}$ Other neurosurgeons and institutions have embraced a "no treatment" posture for high-grade AVMs, in recognition of a more benign natural history.

Some AVM patients are young with a long life expectancy but they have high-risk features such as silent intralesional hemorrhage, ${ }^{7}$ deep location, or deep drainage, all of which increase the risk of future hemorrhage..$^{5,23,28}$ For these patients, VS-SRS offers a noninvasive option between resection and observation. However, obliteration rates after either SS-SRS or VS-SRS with high-grade AVMs are low (Table 7). ${ }^{1-3,8,10-15,17,21,22,24,25,29-32}$ In a group of 47 patients with large AVMs treated with VS-SRS, "obliteration" rates were $23 \%$ for initial VS-SRS after a mean follow-up of 7.3 years; 16 patients required salvage SRS at a mean interval of 61 months, and overall rates of complete obliteration were $18 \%, 45 \%$, and $56 \%$ at 5,7 , and 10 years, respectively. ${ }^{12}$ In our experience with 69 AVM patients reviewed in a separate report, complete obliteration was observed in just 8 patients (11.6\%) after VS-SRS alone, which is an unsatisfactory cure rate (unpublished data, Seymour et al., International SRS Congress, June 19, 2013).

Volume-staged SRS downgrading followed by microsurgical AVM resection combines 2 treatment strategies that are ineffective or risky alone, but are effective together. This approach was previously reported in 1998 by the Pittsburgh group as a case report. ${ }^{4}$ At our center, this combination was curative in $93.8 \%$ of patients, and the one incomplete resection was deliberate after speech mapping demonstrated involvement of language cortex. The rate of surgical morbidity/mortality in this experience (3 of 16 , $18.8 \%$ ) is similar to that reported with other surgical paradigms like staged embolization and resection, but lower than that reported for high-grade AVMs (Grades IV and 


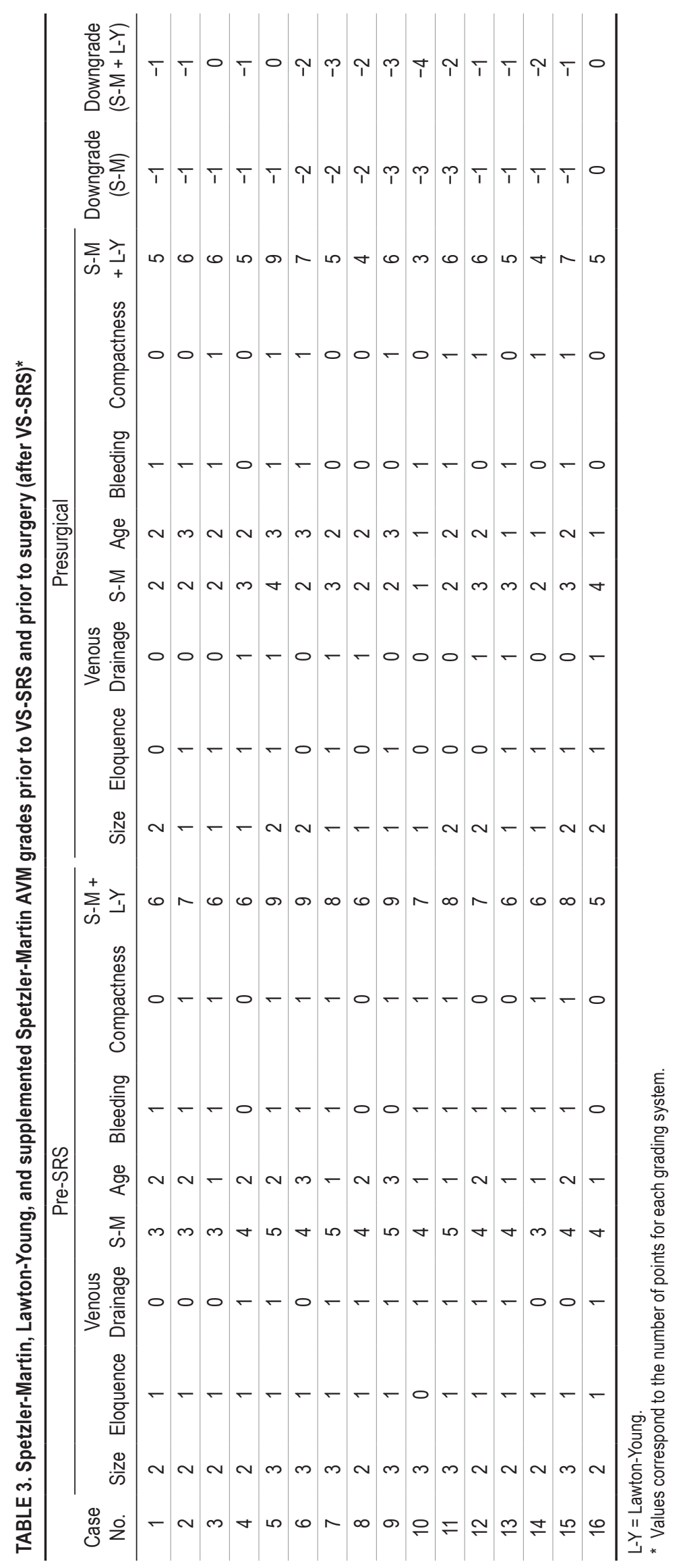



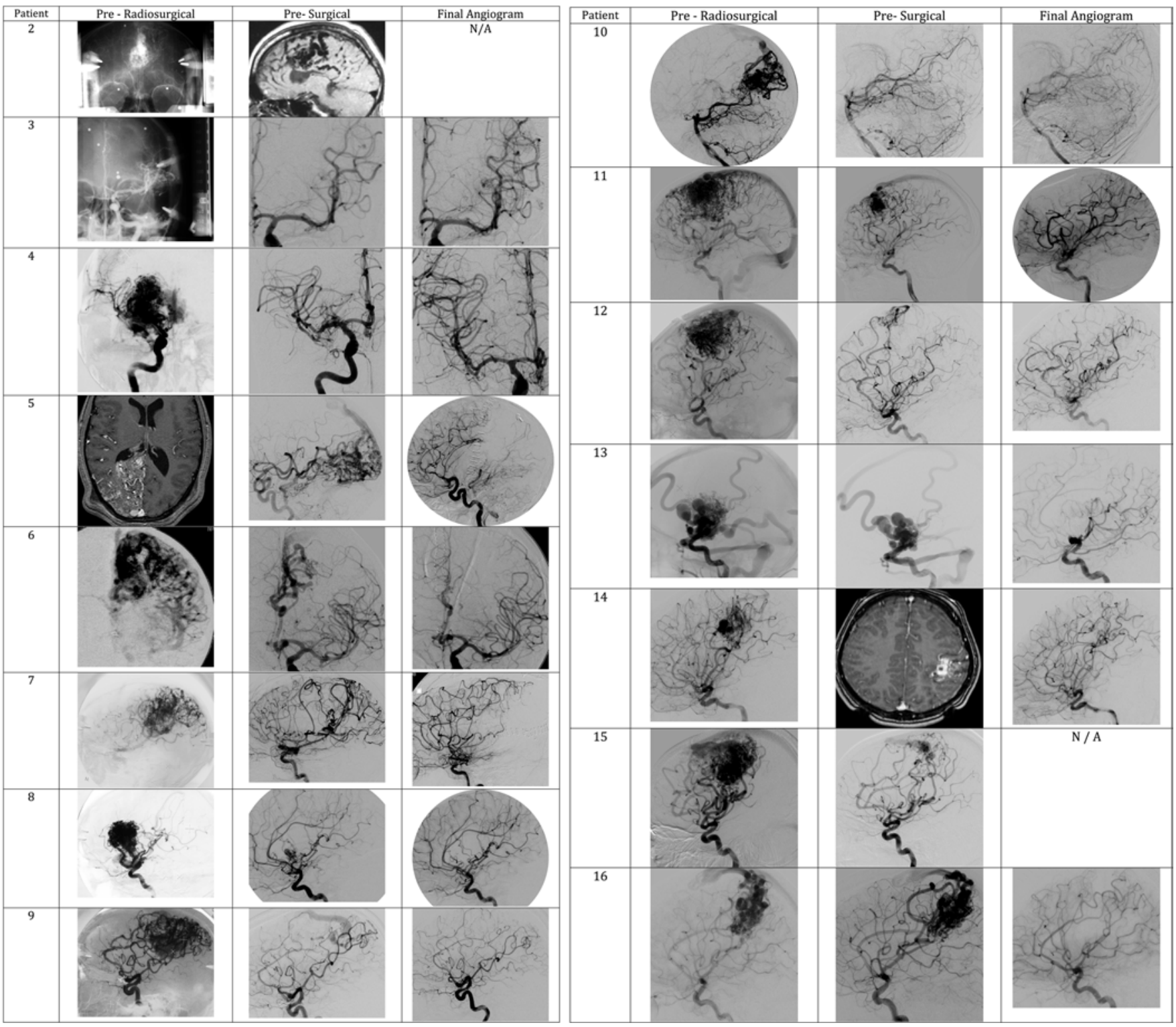

FIG. 2. Initial, postradiosurgical/preoperative, and final angiograms obtained in patients in this experience. N/A = not available.

V) in our previous review of 300 patients for the supplementary grading system (11 of $31,35.5 \%) .{ }^{18}$

\section{AVM Downgrading}

A dictum of the Spetzler-Martin grading system ${ }^{26}$ is

TABLE 4. Outcomes of VS-SRS without and with microsurgical AVM resection*

\begin{tabular}{lccc}
\hline & \multicolumn{2}{c}{ No. of Patients (\%) } & \\
\cline { 2 - 3 } \multicolumn{1}{c}{ Outcome } & $\begin{array}{c}\text { VS-SRS } \\
\text { Alone }(\mathrm{n}=58)\end{array}$ & $\begin{array}{c}\text { VS-SRS + Surgery } \\
(\mathrm{n}=16)\end{array}$ & p Value \\
\hline Cure & $8(13.8)$ & $15(93.8)$ & $<0.0001$ \\
\hline Death & $11(19)$ & $2(12.5)$ & 0.72 \\
\hline $\begin{array}{c}\text { Post-VS-SRS } \\
\text { hemorrhage }\end{array}$ & $17(29.3)$ & $4(25)$ & 1.0 \\
\hline
\end{tabular}

* The value in boldface is statistically significant. that an AVM's grade is defined by discrete anatomy and remains constant and immutable throughout ongoing interventions. Our experience demonstrates that VS-SRS can change AVM grade, with $94 \%$ of our cases having lower Spetzler-Martin scores after initial treatment. Most downgrades were due to reductions in nidus size: 13 AVMs lost points for size, including 3 that lost 2 points. Size reduction converted 5 eloquent AVMs into noneloquent AVMs, and occlusion of deep draining veins decreased AVM grade in 3 patients.

Our experience also demonstrates that VS-SRS changes an AVM's supplementary grade, but unlike the SpetzlerMartin grade that only decreases after radiation, the supplementary grade can move in either direction. Patient age can only increase, and 5 patients added a point during long latency periods. Hemorrhage during the latency period resulted in the loss of a point in 3 patients with previously unruptured AVMs, and 3 diffuse AVMs compacted as 


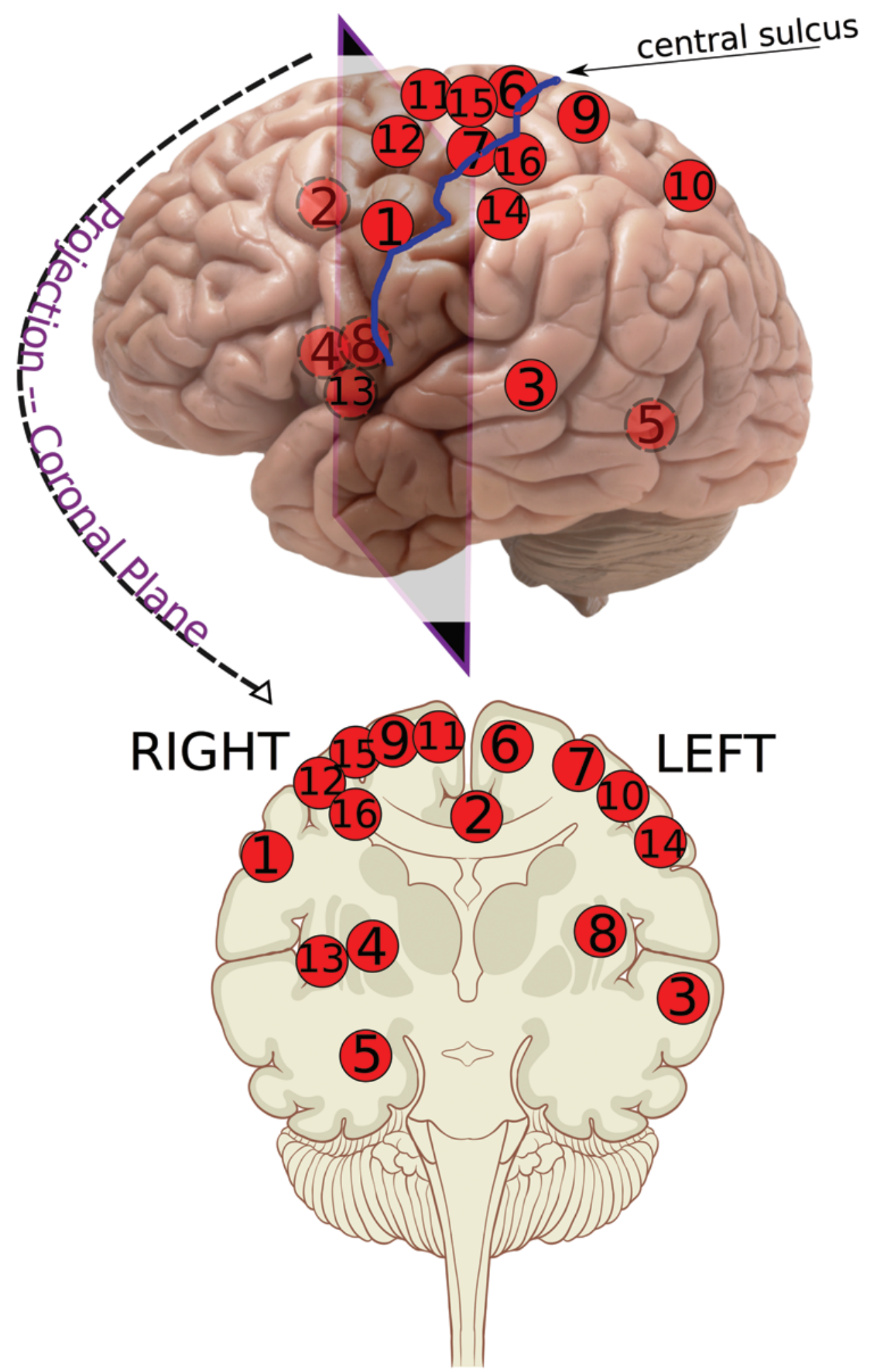

FIG. 3. Visual depiction of all AVMs in this series based on initial locations. Upper: Approximate locations of the high-grade AVMs prior to treatment are given. The solid circles denote convexity or cortical location, and the broken circles denote medial or deep location. Lower: The approximate locations are projected onto the coronal plane. The numbers represent the case numbers in this series as listed in Table 2 and Fig. 2. The upper half of figure has been modified (built upon) from an open license for artwork under Creative Commons Attribution 2.0 License. No usage restrictions. Creative credit: Brain by_DJ_via Creative Commons. http://www.flickr.com/photos/flamephoenix1991. http://creativecommons.org/licenses/by/2.0. The lower half of figure has been modified (built upon) from an open license for artwork under Creative Commons Attribution 2.5 License 2006; no usage restrictions. Creative credits: Patrick J. Lynch, medical illustrator; C. Carl Jaffe, MD, cardiologist. http://creativecommons.org/licenses/ by $/ 2.5 /$. 
TABLE 5. Expected morbidity versus actual morbidity based on Spetzler-Martin grade

\begin{tabular}{|c|c|c|c|c|c|c|c|c|}
\hline \multirow[b]{3}{*}{ S-M Grade } & \multirow{3}{*}{$\begin{array}{l}\text { Morbidity } \\
\text { Rate }^{*}\end{array}$} & \multicolumn{4}{|c|}{ Presentation Grade } & \multicolumn{3}{|c|}{ Preop Grade (after VS-SRS) } \\
\hline & & \multirow{2}{*}{$\begin{array}{c}\text { No. of } \\
\text { Patients }\end{array}$} & \multirow[b]{2}{*}{ Expected Morbidity } & \multicolumn{2}{|c|}{ Actual Morbidity } & \multirow{2}{*}{$\begin{array}{c}\text { No. of } \\
\text { Patients }\end{array}$} & \multirow[b]{2}{*}{ Expected Morbidity } & \multirow{2}{*}{$\begin{array}{c}\text { Actual Surgical } \\
\text { Morbidity }\end{array}$} \\
\hline & & & & Total & Surgical & & & \\
\hline 1 & $0 \%$ & 0 & 0 & - & - & 1 & 0 & 0 \\
\hline II & $5 \%$ & 0 & 0 & - & - & 8 & 0.40 & $1(12.5 \%)$ \\
\hline III & $16 \%$ & 4 & 0.64 & $2(50 \%)$ & $1(25 \%)$ & 5 & 0.80 & $2(4)$ \\
\hline IV & $27 \%$ & 8 & 2.16 & $3(37.5 \%)$ & $1(12.5 \%)$ & 2 & 0.54 & 0 \\
\hline V & $31 \%$ & 4 & 1.24 & $1(25 \%)$ & $1(25 \%)$ & 0 & - & - \\
\hline Total & & 16 & $4.04(25.03 \%)$ & $6(37.5 \%)$ & $3(18.8 \%)$ & 16 & $1.74(10.8 \%)$ & $3(18.8 \%)$ \\
\hline
\end{tabular}

* As reported in the paper by Spetzler and Martin.

the nidus shrank. This variability in the direction of point changes resulted in new supplementary grades in only 6 patients (37.5\%), of whom 3 upgraded and 3 downgraded.

Arteriovenous malformation downgrading complicates surgical risk prediction, which is the objective of the Spetzler-Martin grading system. ${ }^{26}$ The initial Spetzler-Martin grade overestimates surgical morbidity associated with downgraded AVMs, whereas the preoperative downgrade underestimates surgical morbidity. Therefore, VS-SRS facilitates surgery and reduces operative morbidity, but not to the full extent of the downgraded AVM. Downgraded AVMs retain some of their original complexity that made them more dangerous.

\section{Microsurgical AVM Resection After VS-SRS}

This treatment paradigm with VS-SRS and microsurgery is effective because radiation induces biological changes that facilitate resection. ${ }^{24,29}$ Intimal hyperplasia and medial hyalinization thicken arterial walls, narrow their lumens, and occlude feeding arteries..$^{24}$ Components of the nidus may obliterate and shrink its active volume. Blood flow through the AVM is reduced, sclerotic arteries are easier to coagulate, and surrounding gliosis creates favorable dissection planes. Perforating arteries that supply the deep borders near white matter tracts are transformed from thin and friable to thick and coagulable. ${ }^{24}$ Diffuse margins can be obliterated by radiation..$^{24}$

These benefits notwithstanding, VS-SRS has important risks and half of the morbidity in our experience occurred after radiosurgery and before surgical intervention. Four hemorrhages occurred in this experience. All were within the 3-year latency period; one caused permanent morbidity, and another resulted ultimately in death. Latency hemorrhage is therefore a concern. This hemorrhagic risk following multiple SRS sessions may be more significant than the risk of radiation-induced complications. ${ }^{16}$ These complications are particularly difficult with high-grade AVMs noted for their lower rate of spontaneous hemorrhage, ${ }^{9}$ and in this cohort selected for its young age and good condition. It remains unclear whether these latency hemorrhages were due to a more dangerous natural history risk attributable to radiation, or to the natural history of an unobliterated AVM.

\section{Limitations}

The indications for radiosurgical downgrading plus microsurgery are narrow and exclude patients who are older, have comorbidities, have previously experienced significant hemorrhage, or have truly inoperable AVMs unlikely to be deemed otherwise after radiosurgery. Pa-

TABLE 6. Expected morbidity versus actual morbidity based on the supplemented Spetzler-Martin grade

\begin{tabular}{|c|c|c|c|c|c|c|c|c|}
\hline \multirow{3}{*}{$\begin{array}{l}\text { Supplemented } \\
\text { S-M Grade }\end{array}$} & \multirow[b]{3}{*}{ Morbidity Rate* } & \multicolumn{4}{|c|}{ Presentation Grade } & \multicolumn{3}{|c|}{ Preop Grade (after VS-SRS) } \\
\hline & & \multirow{2}{*}{$\begin{array}{c}\text { No. of } \\
\text { Patients }\end{array}$} & \multirow{2}{*}{$\begin{array}{l}\text { Expected } \\
\text { Morbidity }\end{array}$} & \multicolumn{2}{|c|}{ Actual Morbidity } & \multirow{2}{*}{$\begin{array}{c}\text { No. of } \\
\text { Patients }\end{array}$} & \multirow{2}{*}{$\begin{array}{l}\text { Expected } \\
\text { Morbidity }\end{array}$} & \multirow{2}{*}{$\begin{array}{c}\text { Actual Surgica } \\
\text { Morbidity }\end{array}$} \\
\hline & & & & Total & Surgical & & & \\
\hline 1 & No data & 0 & 0 & - & - & 0 & 0 & - \\
\hline 2 & $0 \%$ & 0 & 0 & - & - & 0 & 0 & - \\
\hline 3 & $0 \%$ & 0 & 0 & - & - & 1 & 0 & - \\
\hline 4 & $9.1 \%$ & 0 & 0 & - & - & 2 & 0.18 & - \\
\hline 5 & $21.1 \%$ & 1 & 0.21 & $1(100 \%)$ & $1(100 \%)$ & 5 & 1.05 & $2(40 \%)$ \\
\hline 6 & $27.1 \%$ & 6 & 1.63 & $2(33.3 \%)$ & $1(16.7 \%)$ & 5 & 1.35 & - \\
\hline 7 & $54.5 \%$ & 3 & 1.64 & $1(33.3 \%)$ & - & 2 & 1.09 & $1(50 \%)$ \\
\hline 8 & $50 \%$ & 3 & 1.5 & $2(66.6 \%)$ & $1(33.3 \%)$ & 0 & 0 & - \\
\hline 9 & $40 \%$ & 3 & 1.2 & - & - & 1 & 0.4 & - \\
\hline 10 & No data & 0 & 0 & - & - & 0 & 0 & - \\
\hline Total & & 16 & $6.18(38.6 \%)$ & $6(37.5 \%)$ & $3(18.8 \%)$ & 16 & $4.07(25.4 \%)$ & $3(18.8 \%)$ \\
\hline
\end{tabular}

* As reported in the paper by Lawton et al. 
TABLE 7. Literature review of SRS for high-grade and eloquent AVMs or those requiring more than one stage of SRS

\begin{tabular}{|c|c|c|c|}
\hline Authors \& Year & Obliteration Rate & Post-SRS Hemorrhage Rate & Median Follow-Up \\
\hline \multicolumn{4}{|c|}{$\begin{array}{l}\text { Deep AVM SRS: thalamus, basal ganglia, } \\
\text { internal capsule }\end{array}$} \\
\hline Kano et al., $2012^{14}$ & $72 \%$ & $15.4 \%$ & $81 \mathrm{mos}$ \\
\hline Kiran et al., 2009 & $74 \%$ & $9.4 \%$ & $28 \mathrm{mos}$ \\
\hline Zabel-du Bois et al., 2006 & $65 \%$ & $9.2 \%$ & $36 \mathrm{mos}$ \\
\hline Andrade-Souza et al., 2005 & $61.9 \%$ & $14.3 \%$ & 39 mos \\
\hline Pollock et al., 2004 & $\begin{array}{l}66 \% \text { ( } 48 \% \text { obliteration rate w/o any new } \\
\text { deficit) }\end{array}$ & $12 \%$ & 45 mos \\
\hline \multicolumn{4}{|l|}{ Brainstem AVM SRS } \\
\hline Kano et al., $2012^{15}$ & $76 \%$ & $6 \%$ & 72 mos \\
\hline Kiran et al., 2009 & $74 \%$ & $9.4 \%$ & $28 \mathrm{mos}$ \\
\hline Pollock et al., 2004 & $\begin{array}{l}66 \% \text { ( } 48 \% \text { obliteration rate w/o any new } \\
\text { deficit) }\end{array}$ & $12 \%$ & 45 mos \\
\hline \multicolumn{4}{|l|}{ Eloquent AVMs radiosurgery } \\
\hline Javalkar et al., 2009 & $46.7 \%$ & $10.8 \%$ & $36 \mathrm{mos}$ \\
\hline \multicolumn{4}{|l|}{ Motor strip AVM SRS } \\
\hline Andrade-Souza et al., 2006 & $60.5 \%$ & $7.9 \%$ & $42.4 \mathrm{mos}$ \\
\hline Hadjipanayis et al., 2001 & $70 \%$ & $6.1 \%$ & $54 \mathrm{mos}$ \\
\hline Zabel-du Bois et al., 2006 & $65 \%$ & $9.2 \%$ & 36 mos \\
\hline \multicolumn{4}{|l|}{ VS-SRS for AVMs } \\
\hline Pollock et al., 2000 & $\begin{array}{l}\text { Decrease in 12-Gy AVM \& non-AVM } \\
\text { vol of } 11.1 \% \text { \& } 27.2 \%\end{array}$ & & \\
\hline Kano et al., $2012^{12}$ & $36.2 \% ; 56 \%$ after repeat SRS & $21 \%$ & $87 \mathrm{mos}$ \\
\hline Sirin et al., 2008 & $50 \%$ (total); $29 \%$ (near total) & $14 \%$ & 50 mos after last stage of SRS \\
\hline Chung et al., 2008 & $33.3 \%$ & $16.7 \%$ & $28 \mathrm{mos}$ \\
\hline Kano et al., 2013 & $36 \% ; 66 \%$ after repeat SRS & $17 \%$ & 87 mos after second stage SRS \\
\hline Yamamoto et al., 2012 & $65 \%$ & $76.2 \%$ & 105 mos \\
\hline \multicolumn{4}{|l|}{ SRS \& subsequent surgery for AVMs } \\
\hline Steinberg et al., 1996 & $84.8 \%$ after resection & $24 \%$ (in latency period) & $\begin{array}{l}\text { AVMs were less vascular, par- } \\
\text { tially thrombosed, \& more eas- } \\
\text { ily resected in SRS patients }\end{array}$ \\
\hline Sanchez-Mejia et al., 2009 & $\begin{array}{l}\text { Mean AVM vol reduced by } 78 \% \text { \& } \\
\text { S-M grade reduced in } 52 \% \text { of SRS } \\
\text { patients. Decreases in preop embo- } \\
\text { lization, mean op time, blood loss, } \\
\text { surgical morbidity, length of hospital } \\
\text { stay in SRS patients. }\end{array}$ & $\begin{array}{l}\text { Improved mRS scores in SRS } \\
\text { patients. SRS patients at } \\
\text { risk of hemorrhage during } \\
\text { latency period. }\end{array}$ & 128 mos \\
\hline \multicolumn{4}{|l|}{ Repeat SRS for AVMs } \\
\hline Kano et al., $2012^{13}$ & $80 \%$ & $\begin{array}{l}7 \% \text { btwn initial \& repeat; } 16 \% \\
\text { after repeat }\end{array}$ & $80 \mathrm{mos}$ \\
\hline \multicolumn{4}{|l|}{ Giant AVMs radiosurgery } \\
\hline Xiao et al., 2010 & $0 \%$ (complete) & $5 \%$ & $32 \mathrm{mos}$ \\
\hline
\end{tabular}

tients managed with this strategy were highly selected based on AVM anatomy, clinical presentation, treatment course, and response to radiosurgery. Therefore, this is a small series. It is impossible to predict upfront patients who will respond favorably to radiation therapy, remain uncured, and meet criteria to advance to resection. In more recent years, a change in the VS-SRS strategy resulted in more AVM downgrading. Decreased volume per stage $(<$
$8-10 \mathrm{~cm}^{3}$ ) and higher dose per fraction (> $17 \mathrm{~Gy}$ ) improved responses compared with earlier treatment and may enable more patients with incomplete AVM obliteration to advance to surgical intervention at 3 years.

In a clinical experience limited by its sample size, it is difficult to clearly measure morbidity associated with this VS-SRS plus surgery paradigm, or compare this morbidity with natural history risks in a matched control group. Our 
institutional experience with radiosurgery and microsurgery created a unique opportunity to accumulate a sizable group of rare patients within a single center. This treatment paradigm for high-grade AVM patients should be studied further in a multicenter, prospective, observational trial, but this will be difficult in the aftermath of the ARUBA trial. ${ }^{20}$ We conclude that volume-staged radiosurgical downgrading with microsurgical resection is a reasonable option to propose to selected patients with long life expectancy and high-risk anatomical features.

\section{Conclusions}

Volume-staged SRS can be considered a prelude to surgery for large AVMs, with the aim of reducing nidus size. For those patients with favorable response to radiation therapy without cure, the surgical cure rate is high (94\%) and the complication profile seems acceptable. This experience demonstrates that high-grade AVMs can be treated with a strategy that begins with VS-SRS and the intent to downgrade the AVM for microsurgical resection, offering an acceptable treatment paradigm for patients with these challenging AVMs.

\section{References}

1. Andrade-Souza YM, Ramani M, Scora D, Tsao MN, TerBrugge K, Schwartz ML: Radiosurgical treatment for rolandic arteriovenous malformations. J Neurosurg 105:689-697, 2006

2. Andrade-Souza YM, Zadeh G, Scora D, Tsao MN, Schwartz ML: Radiosurgery for basal ganglia, internal capsule, and thalamus arteriovenous malformation: clinical outcome. Neurosurgery 56:56-64, 2005

3. Chung WY, Shiau CY, Wu HM, Liu KD, Guo WY, Wang LW, et al: Staged radiosurgery for extra-large cerebral arteriovenous malformations: method, implementation, and results. J Neurosurg 109 Suppl:65-72, 2008

4. Firlik AD, Levy EI, Kondziolka D, Yonas H: Staged volume radiosurgery followed by microsurgical resection: a novel treatment for giant cerebral arteriovenous malformations: technical case report. Neurosurgery 43:1223-1228, 1998

5. Fleetwood IG, Marcellus ML, Levy RP, Marks MP, Steinberg GK: Deep arteriovenous malformations of the basal ganglia and thalamus: natural history. J Neurosurg 98:747-750, 2003

6. Fogh S, Ma L, Gupta N, Sahgal A, Nakamura JL, Barani I, et al: High-precision volume-staged Gamma Knife surgery and equivalent hypofractionation dose schedules for treating large arteriovenous malformations. J Neurosurg 117 Suppl:115-119, 2012

7. Guo Y, Saunders T, Su H, Kim H, Akkoc D, Saloner DA, et al: Silent intralesional microhemorrhage as a risk factor for brain arteriovenous malformation rupture. Stroke 43:12401246,2012

8. Hadjipanayis CG, Levy EI, Niranjan A, Firlik AD, Kondziolka D, Flickinger JC, et al: Stereotactic radiosurgery for motor cortex region arteriovenous malformations. Neurosurgery 48:70-77, 2001

9. Han PP, Ponce FA, Spetzler RF: Intention-to-treat analysis of Spetzler-Martin Grades IV and V arteriovenous malformations: natural history and treatment paradigm. J Neurosurg 98:3-7, 2003

10. Javalkar V, Pillai P, Vannemreddy P, Caldito G, Ampil F, Nanda A: Gamma knife radiosurgery for arteriovenous malformations located in eloquent regions of the brain. Neurol India 57:617-621, 2009
11. Kano H, Kondziolka D, Flickinger JC, Park KJ, Parry PV, Yang HC, et al: Multistaged volumetric management of large arteriovenous malformations. Prog Neurol Surg 27:73-80, 2013

12. Kano H, Kondziolka D, Flickinger JC, Park KJ, Parry PV, Yang HC, et al: Stereotactic radiosurgery for arteriovenous malformations, Part 6: multistaged volumetric management of large arteriovenous malformations. J Neurosurg 116:5465,2012

13. Kano H, Kondziolka D, Flickinger JC, Yang HC, Flannery TJ, Awan NR, et al: Stereotactic radiosurgery for arteriovenous malformations, Part 3: outcome predictors and risks after repeat radiosurgery. J Neurosurg 116:21-32, 2012

14. Kano H, Kondziolka D, Flickinger JC, Yang HC, Flannery TJ, Niranjan A, et al: Stereotactic radiosurgery for arteriovenous malformations, Part 4: management of basal ganglia and thalamus arteriovenous malformations. J Neurosurg 116:33-43, 2012

15. Kano H, Kondziolka D, Flickinger JC, Yang HC, Flannery TJ, Niranjan A, et al: Stereotactic radiosurgery for arteriovenous malformations, Part 5: management of brainstem arteriovenous malformations. J Neurosurg 116:44-53, 2012

16. Karlsson B, Jokura H, Yamamoto M, Söderman M, Lax I: Is repeated radiosurgery an alternative to staged radiosurgery for very large brain arteriovenous malformations? J Neurosurg 107:740-744, 2007

17. Kiran NA, Kale SS, Kasliwal MK, Vaishya S, Gupta A, Singh Sharma M, et al: Gamma knife radiosurgery for arteriovenous malformations of basal ganglia, thalamus and brainstem-a retrospective study comparing the results with that for AVMs at other intracranial locations. Acta Neurochir (Wien) 151:1575-1582, 2009

18. Lawton MT, Kim H, McCulloch CE, Mikhak B, Young WL: A supplementary grading scale for selecting patients with brain arteriovenous malformations for surgery. Neurosurgery 66:702-713, 2010

19. Miyawaki L, Dowd C, Wara W, Goldsmith B, Albright N, Gutin P, et al: Five year results of LINAC radiosurgery for arteriovenous malformations: outcome for large AVMS. Int J Radiat Oncol Biol Phys 44:1089-1106, 1999

20. Mohr JP, Parides MK, Stapf C, Moquete E, Moy CS, Overbey JR, et al: Medical management with or without interventional therapy for unruptured brain arteriovenous malformations (ARUBA): a multicentre, non-blinded, randomised trial. Lancet 383:614-621, 2014

21. Pollock BE, Gorman DA, Brown PD: Radiosurgery for arteriovenous malformations of the basal ganglia, thalamus, and brainstem. J Neurosurg 100:210-214, 2004

22. Pollock BE, Kline RW, Stafford SL, Foote RL, Schomberg PJ: The rationale and technique of staged-volume arteriovenous malformation radiosurgery. Int J Radiat Oncol Biol Phys 48:817-824, 2000

23. Potts MB, Young WL, Lawton MT: Deep arteriovenous malformations in the basal ganglia, thalamus, and insula: microsurgical management, techniques, and results. Neurosurgery 73:417-429, 2013

24. Sanchez-Mejia RO, McDermott MW, Tan J, Kim H, Young WL, Lawton MT: Radiosurgery facilitates resection of brain arteriovenous malformations and reduces surgical morbidity. Neurosurgery 64:231-240, 2009

25. Sirin S, Kondziolka D, Niranjan A, Flickinger JC, Maitz AH, Lunsford LD: Prospective staged volume radiosurgery for large arteriovenous malformations: indications and outcomes in otherwise untreatable patients. Neurosurgery 58:17-27, 2006

26. Spetzler RF, Martin NA: A proposed grading system for arteriovenous malformations. J Neurosurg 65:476-483, 1986

27. Spetzler RF, Martin NA, Carter LP, Flom RA, Raudzens PA, 
Wilkinson E: Surgical management of large AVM's by staged embolization and operative excision. J Neurosurg 67:17-28, 1987

28. Stapf C, Mast H, Sciacca RR, Choi JH, Khaw AV, Connolly ES, et al: Predictors of hemorrhage in patients with untreated brain arteriovenous malformation. Neurology 66:1350-1355, 2006

29. Steinberg GK, Chang SD, Levy RP, Marks MP, Frankel K, Marcellus M: Surgical resection of large incompletely treated intracranial arteriovenous malformations following stereotactic radiosurgery. J Neurosurg 84:920-928, 1996

30. Xiao F, Gorgulho AA, Lin CS, Chen CH, Agazaryan N, Vinuela $\mathrm{F}$, et al: Treatment of giant cerebral arteriovenous malformation: hypofractionated stereotactic radiation as the first stage. Neurosurgery 67:1253-1259, 2010

31. Yamamoto M, Akabane A, Matsumaru Y, Higuchi Y, Kasuya $\mathrm{H}$, Urakawa Y: Long-term follow-up results of intentional 2-stage Gamma Knife surgery with an interval of at least 3 years for arteriovenous malformations larger than $10 \mathrm{~cm}^{3} . \mathbf{J}$ Neurosurg 117 Suppl:126-134, 2012

32. Zabel-du Bois A, Milker-Zabel S, Huber P, Schlegel W, Debus J: Stereotactic linac-based radiosurgery in the treatment of cerebral arteriovenous malformations located deep, involving corpus callosum, motor cortex, or brainstem. Int J Radiat Oncol Biol Phys 64:1044-1048, 2006

\section{Author Contributions}

Conception and design: Lawton, Abla, Sneed, Larson, McDermott. Acquisition of data: Lawton, Abla, Rutledge, Seymour, Guo, Kim. Analysis and interpretation of data: Lawton, Abla, Rutledge. Drafting the article: Lawton, Abla, Gupta, McDermott. Critically revising the article: all authors. Reviewed submitted version of manuscript: all authors. Approved the final version of the manuscript on behalf of all authors: Lawton. Statistical analysis: Lawton, Abla, Rutledge, Seymour. Administrative/technical/material support: Lawton, Abla, Rutledge, Gupta, Sneed, Barani, Larson, McDermott. Study supervision: Lawton, Abla, Gupta, Sneed, Barani, Larson, McDermott.

\section{Correspondence}

Michael T. Lawton, Department of Neurosurgery, University of California San Francisco, 505 Parnassus Ave., M780, San Francisco, CA 94143. email: lawtonm@ neurosurg.ucsf.edu. 